\title{
URBAN LAND RECAPITALIZATION AND REGIONAL UNIFIED TRANSIT NETWORK - AN IMPERATIVE ACTION FOR THE NEW YORK CITY LONG-TERM COMPETITIVENESS
}

\author{
J.C.Venturi ${ }^{1}$, E.Chao ${ }^{2 *}$ and C.Calvin ${ }^{3}$ \\ ${ }^{I}$ Rethink Studio, New York, U.S.A \\ ${ }^{2}$ Finance Department, The Wharton Business School, Philadelphia, U.S.A \\ ${ }^{3}$ Finance Department, Waseda University, Tokyo, Japan \\ * Corresponding author
}

\begin{abstract}
Public transport is an asset with national significance and a dominant engine for economic productivity. Urban areas are the centers of economic, industrial, governmental, and cultural activities, their developments belong to the national level. Many global cities are either in the transition stage of repositioning cities' long-term competitiveness or in the development stage of large-scale metropolitan planning. In the United States, the New York City (NYC) and the Tristates (New York, New Jersey, and Connecticut) are simultaneously facing these two-dimensional challenges. Common facts have been found in these two settings: the outstanding commitments on the modernization of efficient urban transit systems and the transformative mindset to recapitalize city's assets: both developable and underutilized lands within the central business districts (CBDs) and surroundings. The article marries both economic perspective and engineering discipline. The analyses on urban formation reach the following discussions. First, the definitions, reviews, and evaluation of growth obstacles represent that the necessities to turn independent line operation into a cohesive unified trunk network are feasible and well-thought out. Second, an introduction and comparative analyses across independent lines vs. integrated network, trunk vs. branch lines operation, single nucleus vs. multi-satellite cities associated with regional rail systems are presented. Third, architectural and engineering uplifts on station design, platform expansion, track reengineering, and network realignment at the underperforming Pennsylvania Station are comprehensively studied. It is, now, time to pay a systematic attention to the transformative process of repositioning the NYC long-term competitiveness.
\end{abstract}

\section{Introduction}

The opinions on a large-scale rail transit network planning, design and operation vary the transit systems geometric shape and service strategies, which influence future patterns of urban development and city functionality. Studying the evolution of rail transit network in cities can provide valuable lessons for new projects, including the choice of appropriate transit modes and the design of network efficiency. Digesting the historical land use theories from distinguished experts, a critical topic has not yet been discussed. That is, how could a through-running station and a regional unified network (RUN) generate longterm sustainable growth for a city and overall region. The article presents a surgical diagnosis of the recent NYC' economy stagnation and pinpoints a series of countermeasures to unlock the economic values by recapitalizing underutilized land and creating a regional unified network (RUN) to further increase service coverage, regional connectivity, and economic productivity. The process is a transformative measure to increase urban land and asset utilization, which is an imperative action for the NYC and Tristates' long-term competitiveness.

First, the definitions, reviews, and evaluation of growth obstacles represent that the necessities to turn independent line operation into a cohesive unified trunk network are feasible and well-thought out. Second, a series of NYC' case studies and international comparative analyses across independent lines vs. integrated network, trunk vs. branch lines operation, single nucleus vs. multi-satellite cities associated with regional rail systems are presented. Third, architectural and engineering uplifts on station design, platform expansion, track reengineering, and network realignment at the underperforming Pennsylvania Station are comprehensively studied. It is, now, time to pay a systematic attention to the transformative process of repositioning the NYC long-term competitiveness.

\section{Existing conditions and growth obstacles of the NYC and regions}

\subsection{Overloaded capacity on a single nucleus}

The regional rail network is currently operating on a single nucleus, rather than unifying an entire region. When a single nucleus starts to reach its system capacity, it is intuitively to divert and redistribute the rapid growing demand. To ensure the demand would be successfully distributed, a development of trunk and branch lines need to be planned and efficiently operated. Instead, the NYC and Tristate regional rail systems are not only operating on a single nucleus point, but disconnecting one from another as shown in Figure 1. For example, for passengers wish to commute from the Northern part of the Manhattan to Long Island, they would have to encounter an overcrowded Grand Central station, and either 
walk 8 blocks down or take a clogging subway to the inefficient Pennsylvania Station located in the core of the Manhattan CBD, and then ride on the Long Island Rail Road (LIRR). This fragmented region is unable to provide sufficiently access to both systems; therefore, squander the potential of the existing transportation network and hobble regional development.

Figure 1. New York Regional Rail Network: Comparison of single vs. multi-nucleus development

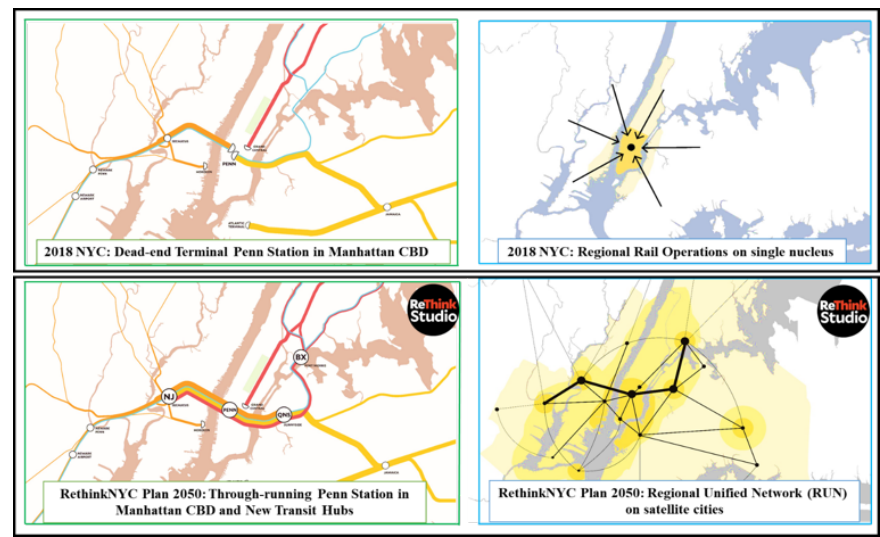

2.2 Using low capacity mode to support fast-growing travel demand

New York City's current transit systems and network are unable to accommodate the rising ridership demand. To commute in and out of Manhattan, common choices are either by rail or bus. Pennsylvania Station is a dead-end terminal located in the center of downtown Manhattan. Regional rails include Amtrak, New Jersey Transit (NJT), Long Island Rail Road (LIRR), and Metro-North Railroad, carry millions of daily commuters in-and-out of Manhattan. The network efficiency on operating flexibility, continuity of lines, and transfers at Penn station is low. Train movements at Penn station are inefficient due to the design and inflexible track alignments, resulting in low fleet utilization. If commuting inand-out of Manhattan via the rail network becomes difficult and commuters relying on low capacity ROW-C bus face even more delays. In fact, buses, on both peak and off-peak commuter times are "parked" on the toll plaza and Lincoln tunnel as shown in Figure 3. Commuters spend about extra 60120 minutes to enter and exit Manhattan on a daily basis (CBS NY, 2015; NY Business Journal, 2015; NBC NY, 2017). The New York Port Authority is currently bringing commuters through the already heavily congested Lincoln tunnel to the downtown Manhattan bus terminal, instead of using high capacity ROW-A rail transit through the Trans-Hudson gateway tunnel to the Pennsylvania Station as shown in Figure 2. These delays associate with the various modes of transit result in lost productivity as commuters spend unproductive time in travel.
Figure 2. New York Regional Rail Existing vs. Proposed Commuting Plan

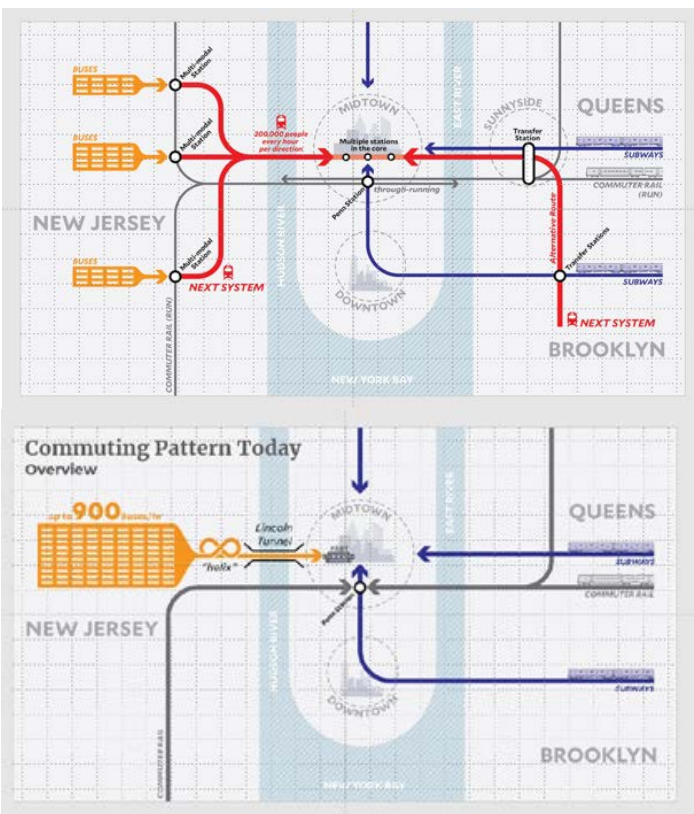

Figure 3: Aerial footage on Lincoln tunnel (inbound) Source: Wikipedia ${ }^{1}$, New York Business Journal ${ }^{2}, \mathrm{CBS}^{3}$, NBC New York

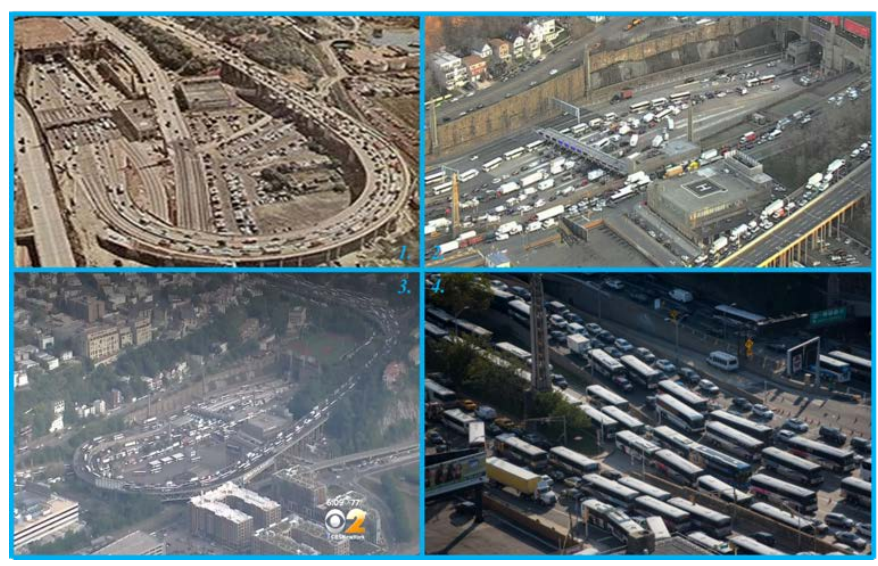

2.3 Managerial issues on interagency administration and collaboration

Besides the disconnection of region rails and utilization of low capacity bus to support in-and-out commutes, these hazardous phenomena were due to the incumbent transit agencies are keep running their own agendum (New Jersey Commuter Organization, 2016; New Jersey Business Journal, 2017; North New Jersey Daily News, 2017; Rethink Studio, 2017), which caused the unnecessary administrative cost and lack of interagency consolidation. U.S. cities, unlike Russia and Chinese cities, have encountered high administrative costs and managerial barriers due to the complexity of multilateral transit agencies decision making hierarchy as shown on Figure 4. A relentless efforts must be devoted to understanding of the roles and characteristics of different transportation modes, their impact on the long-term sustainable growth to the metropolitan areas, and the network efficiency on regional connectivity. This needs to happen while avoiding mutually conflicting policies and multilateral communication mechanism to 
generate a united, efficient, and integrated transit network to maximize customers' gain.

Figure 4. The incumbent transit agencies in the New York Metropolis

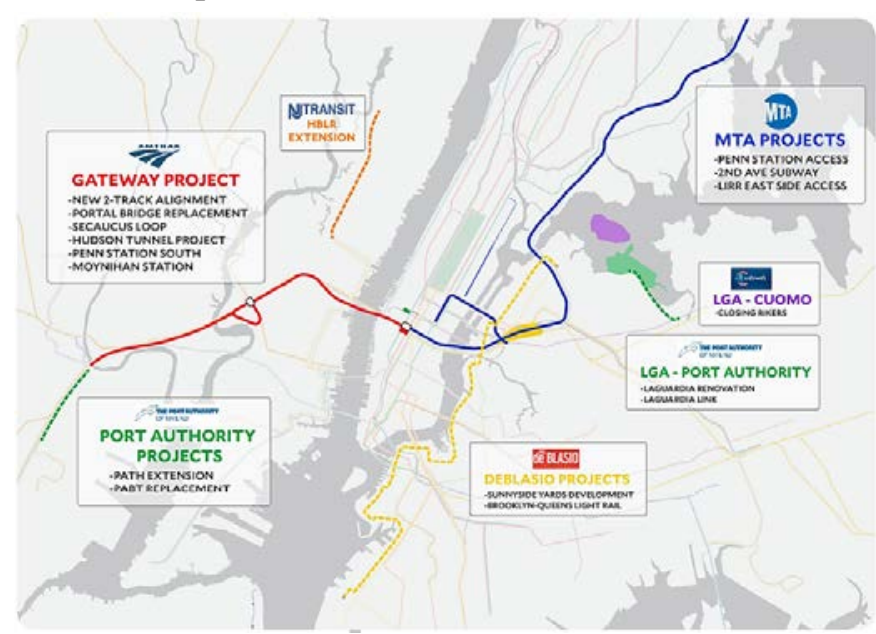

\section{Necessity of integrated transit network}

Passenger transfers among lines involve a certain "resistance", because a transfer may cause delay and require passenger reorientation and extra walking between mezzanines and platforms on different lines. Therefore, it is sometimes believed that transfers are undesirable and should be avoided whenever possible.

In fact, transit networks with many transfer opportunities offer passengers a much greater selection of travel paths than networks with disconnected lines which involve no transferring. The more transferring is performed, the greater is network efficiency, because each line can be designed optimally for its physical conditions, operating strategy and ridership demand. When transfers are planned correctly, passenger resistance can be easily outweighed by the benefit from line alignments, schedules, and eventually in better services offered. Passenger transfers among lines represent an important element of transit travel. The importance of transfers has been clearly demonstrated by the fact that most successful large transit networks, such as Munich, San Francisco, Washington, and New York rely on extensive intermodal and intramodal transfers. Network integration through transfers includes functional design of lines, optimal layout of transfer stations, and coordinated scheduling and information (Vuchic \& Musso, 1992). To understand how transfers increase network efficiency, the roles of trunk lines and branch (i.e. feeder) lines must also be understood:

- $\quad$ Trunk line: overlapping sections are used by more than one line, usually in city center, and

- $\quad$ Branch line: are separating from the trunk as single lines operate toward the suburbs.

When designing network transfers, the role and difference between independent lines and an integrated network in a large-scale metropolis planning should be thoroughly analyzed:
- Independent line: each line operates by itself between two terminals, and

- Integrated network: where lines overlap, have joint sections or branches.

Although independent lines offer a notable directness of services, not every line has to be independent. Independent lines are more costly to build and may not necessary carry lower O\&M cost (Lehner, 1969).

Integrated network (i.e. regional unified network) consist of lines which merge and diverge, overlap, and frequent contain branches as they leave the city center towards the suburbs (Lee, 1998). It also offers greater area coverage, connectivity, and access to the region. At a large-scale metropolis planning, integrated network is driving the economic value and longterm national competitiveness.

Reasons are as follows: First, branches of lines increase area coverage by rail systems, which are valuable especially in suburban areas where radial lines diverge and single lines cannot serve increasingly large areas. With greater area coverage the network attracts more passengers. As trunk lines usually have short headways (intervals) typically three or four minutes, when it divides into two branches, maintains a sufficiently attractive service with six or eight minute headways. As one or more branches increase total ridership on the line, offered line capacity is increasingly used empty spacekilometers decrease and operating ratio (operation cost divided by fare revenue) increases, as shown in Figure 5 (Vuchic et al., 1976).

Figure 5. Area coverage, load section, capacity, and passenger profile: trunk line with 2 branches

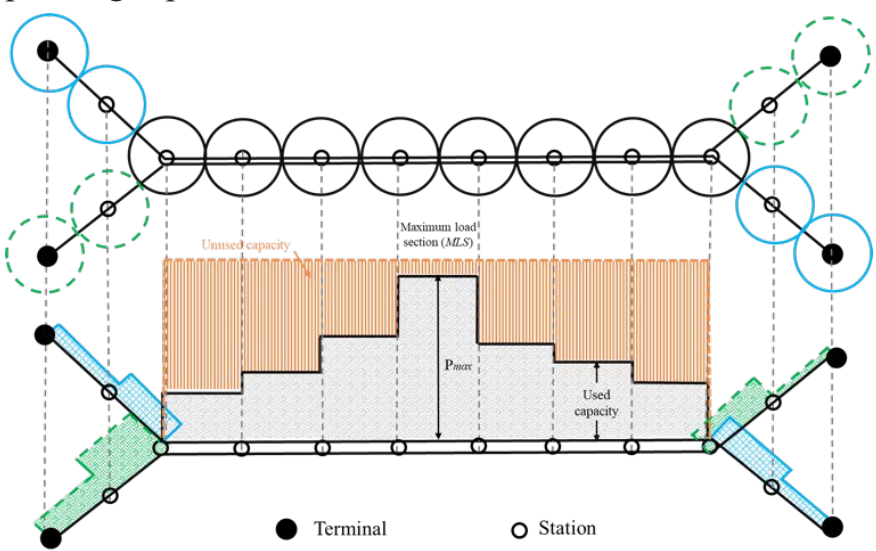

Second, interconnected lines decrease the number of passengers who must transfer among lines at transfer stations. Fewer transfers increases convenience for passengers and decreases dwell times (so called deadhead) of trains in stations, resulting in higher average travel speed (Vuchic, 2005)

Third, rolling stocks operation must interoperate with an integrated network so that different lines can also share maintenance yards and control centers. Metro systems with independent lines have separate control centers and separate yards for each line. Integrated rolling stock, control centers and maintenance facilities have considerable economies of scale 
compared to independent lines (Vuchic, 2014). In all, decisionmaking, to thrive well in the establishment of trunk, branch, independent, and integrated network, needs to strike a good balance between transfers, system connectivity, network performance, and regional integration.

\section{Pennsylvania Station: Breakdown of Existing Challenges and Corresponding Measures}

From the city's functionality and long-term competitiveness perspectives, transit is operating on a series of disjointed parts with limited regional connectivity. To turnaround, the city would require a transformative action to rethink its urban strategies: connect the disconnected parts and increase efficiency gain from an integrated network (Venturi, 2017). The RethinkNYC Plan 2050 explored the geospatial metadata: population distribution, O-D survey, transit connectivity, land use pattern, and future urban growth within the tristate regions, which includes New York, New Jersey, Connecticut. (The Architect Newspaper, 2016; Bloomberg Benchmarks, 2017). The construction phasing plan mapped a series of schematic station design on platform expansion, track reengineering, and network realignment at the underperforming Pennsylvania Station. This section breakdowns three major challenges and provides corresponding engineering measures to convert an independent dead-end terminal to an integrated throughrunning station at Pennsylvania Station.

\subsection{Low Network Capacity vs. Flexible Track Alignment for Higher Operation}

First, the current tracks are operating at maximum network capacity. The inflexible track alignments are impossible to accommodate extra services or any incidental changes. Following trains (FTs) have to wait in tunnels for 15 minutes as leading trains (LTs) exit the station. The station is operating as a terminal rather than as a through station. Trains must cross each other as they enter and leave the station as shown in Figure 6a. The countermeasure of through-running avoids congestion by scheduling eastbound traffic on southern tracks and west-bound traffic on northern tracks shown in Figure $6 \mathrm{~b}$. Each train would enter the station, prepare for passengers boarding and alighting, and continue without ever crossing incoming and outgoing traffic.

Figure 6a. NY Penn Station Dead-end Conflict vs. Figure 6b. Through-running Flow

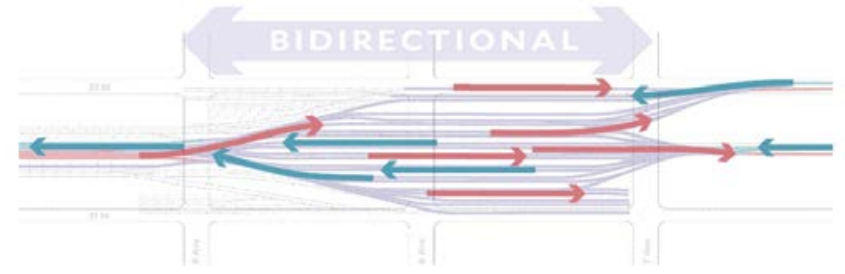

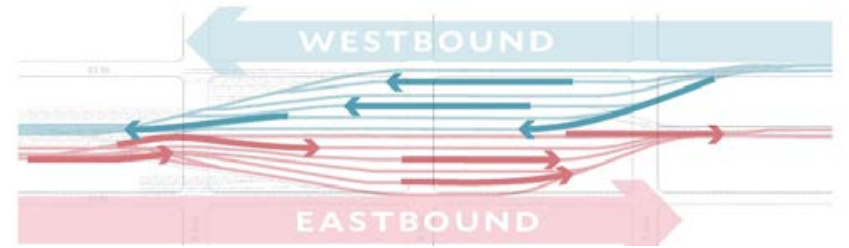

To enable the steady flow of through-running operation, a feasibility study of phasing plan incorporated with track reengineering, network realignment, and minimization of construction and demolition for normal operation are comprehensively examined (Venturi et al, 2017). The study identifies a total of 10 phases to convert the existing independent dead-end terminal to an integrated throughrunning station (Figure 8. Left). Each phase has its counter operating strategy to be followed (Figure 8. Right). The phase plan balances the construction and demolition timelines without disrupting normal commuting services.

\subsection{Limited Passenger Circulation vs. Platform Expansion to Expedite Boarding and Alighting Process}

Second, narrow platforms are considered as a safety issue. Overcrowding on platforms is mitigated through staged boarding, which forces outbound passengers to wait on the mezzanine level until passengers on the leading train are totally alighted. Limited vertical circulation (stairs, escalators) produces chaotic passenger flows and rushed transfers, especially to the NJT passengers as shown in Figure 7a. Without even discussing the possibility of protective screen-door installation, overcrowding drastically reduces system reliability. In contrast, a through-running station would allow single-track configuration to expand the platform width and additional space for vertical circulation as shown in Figure 7b. Such measure offers greater safety and increases passengers' boarding and alighting process at platform and mezzanine levels.

Figure 7a. Penn Station existing platform condition vs. Figure $7 b$. Engineering improvement on vertical circulation

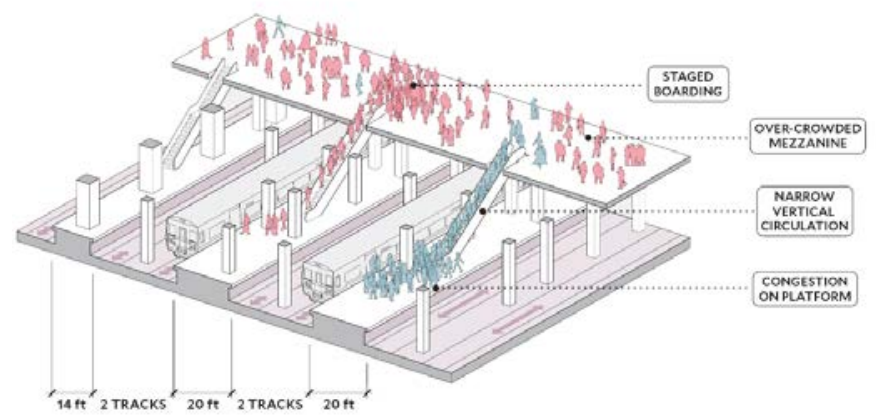




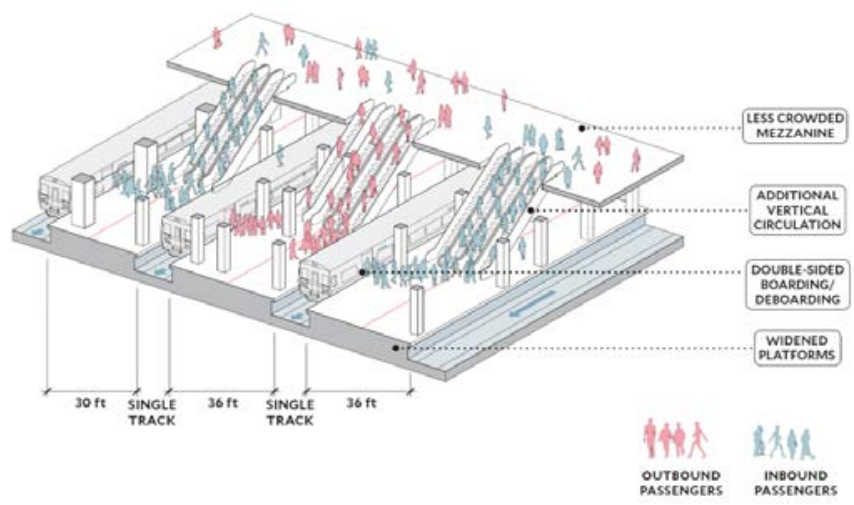

Figure 8. Selective schematic design on track reengineering, network realignment (Left) and counter operation strategy (Right) within the Penn Station Construction Phasing Plan

\section{PHASE 1 OF 10}
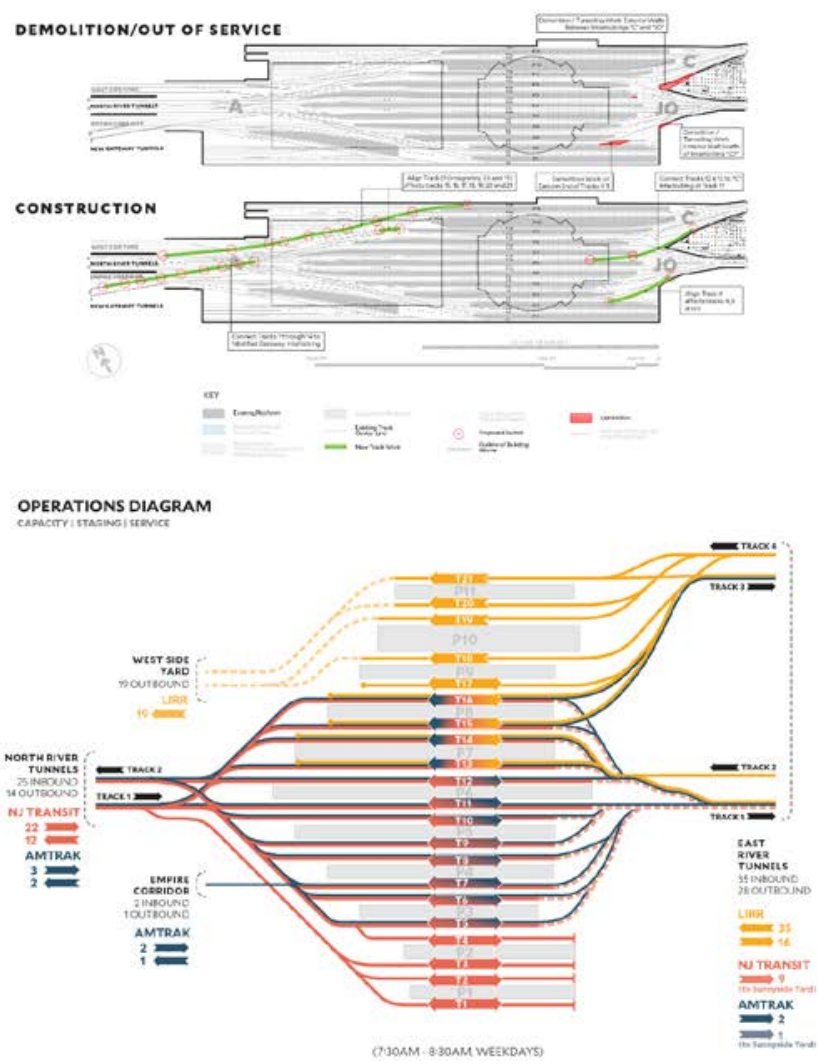

4.3 Disconnected Network Services vs. Unified Network to Increase Regional Connectivity

Third, the New York regional rail services are disconnected. Different landmasses (Manhattan, New Jersey, the Bronx, Long Island) have different transit agencies. Passengers who would like to travel in between New Jersey and Long Island must experience Penn Station's narrow platforms and unreliable boarding and alighting process. To whom would like to transfer from Penn station to Grand Central must use MTA subway. To enable Penn station through-running's capability, the adjustment of terminal functionalities include relocation of railyards, reduction of long dwell times at platforms, and

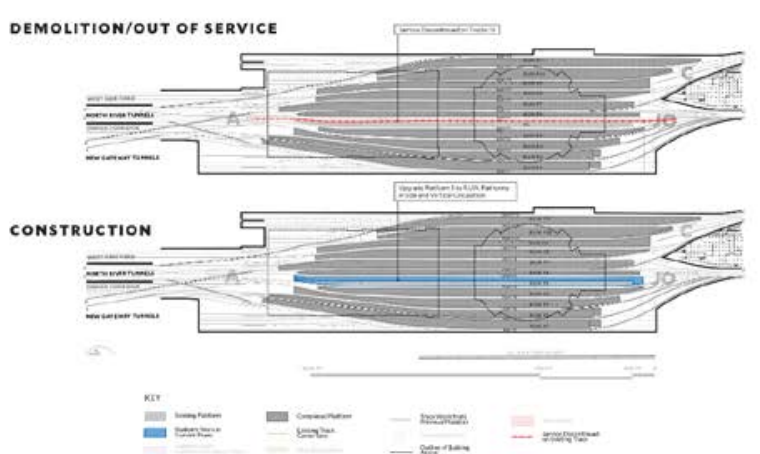

OPERATIONS DIAGRAM

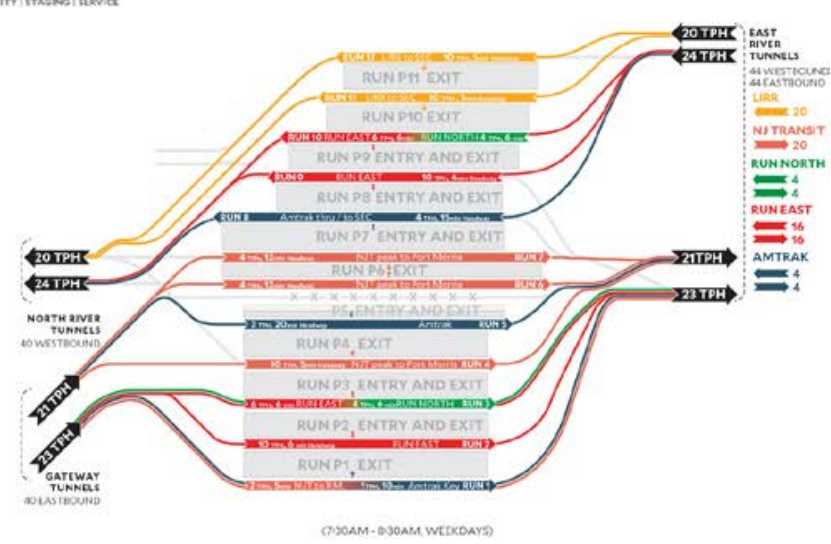

execution of the two abovementioned measures (A \& B). Instead of operating a single nucleus terminal in the center of downtown Manhattan, the plan is to evenly distribute ridership by leveraging the gravity of satellite cities and incubating the growth in Port Morris, the Bronx and Secaucus, where belong to multimodal transit hubs.

The RethinkNYC Plan 2050 addressed the necessity to unify New York regional rail services. The construction phasing plan provided schematic adjustment on platform expansion, track reengineering, and network realignment at the current underperforming Penn Station to enable the through-running services to become a cohesive regional network. In Figure 9. 
tunnel capacity and service density have been increased, regional connectivity has been improved, and fleet utilization has been better performed.

\section{Conclusion}

To recapitalize citywide asset, common efforts have been made in these two settings: the outstanding commitments on the modernization of efficient urban transit systems and the transformative mindset to repurpose city's assets: both developable and underutilized lands within the central business districts (CBDs) and surroundings. The article firstly boiled down the existing New York regional rail operational obstacles, which restricted the overall growth potential of the entire region. The obstacles include overloading the network capacity on a single nucleus - Manhattan, using low capacity mode, bus, to support fast-growing travel demand in-and-out the Manhattan, nonchalantly admitting the managerial issues on interagency administration and collaboration. Second, efficient networks include a combination of independent and integrated lines and trunk lines and branches. Networks having only independent lines without joint sections or branches typically used toward suburbs, are problematic for metropolises' sustainable, long-term economic growth. With the hierarchical analyses of the definition, characteristic, and overall effects on the network operations, a necessity to turn independent line operation into a cohesive unified trunk network in the NY region requires a series of imperative actions.

Figure 9. Comparative analyses of dead-end (Left) vs. through-running (Right) network capacity at the New York Pennsylvania Station
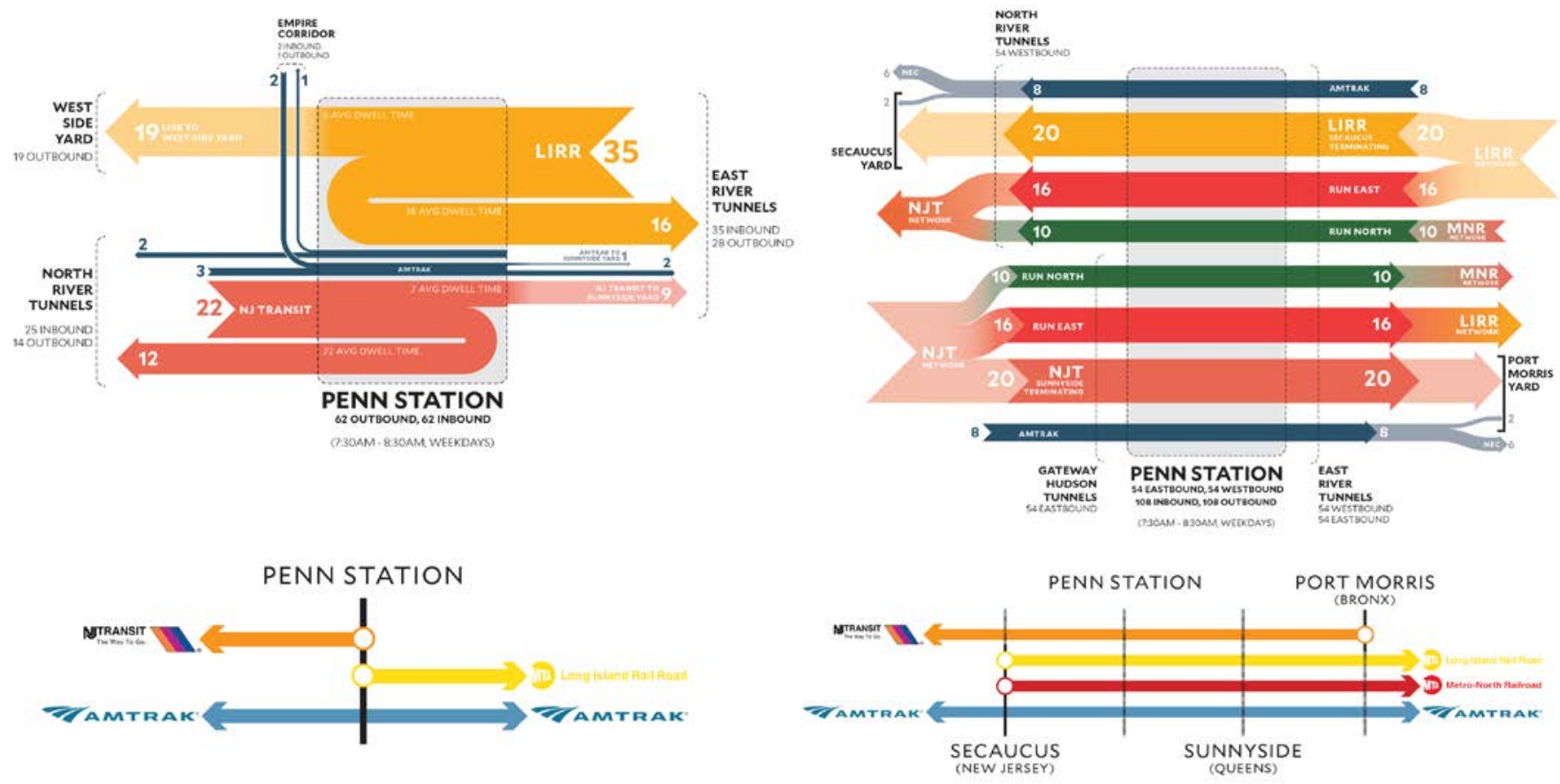

Third, architectural and engineering uplifts on station design, platform expansion, track reengineering, and network realignment at the underperforming Pennsylvania Station craft the countermeasures to transform underutilized asset to an much efficient rail transit station.

The diversity among cities and countries in terms of their historic, geographic, social, and strategic positions dictate the requirements for a variety of approaches and solutions to urban transportation problems. Policies and solutions cannot be directly transferred from one to another; however, many fundamental problems are similar, and the exchange of experience can be useful in resolving the sophisticated problems faced by cities.

Cities around the globe are undergoing a series of transitions. A massive rail network becomes a powerful economic tool to create synergistic values by drastically increasing passenger

and product lucidity and reducing total travel time. A noticeable fact has found that a combination of rail networks with more flexible operation capabilities is able to extract much more economic value from both metropolises and corridors. One of the planning challenges in American cities is that there are too many competing entities and each has its agenda. A simple method to streamlining these competing interests has not yet been found. The inception of the regional and national planning starts by reaching consensus on general guidelines about the type of city and society and then determining the composition of a multimodal system as well as specific plans for each mode.

\section{References}

CBS News (2017) More Tunnels Would Greatly Ease Service Problems At Penn Station, Experts Say. http://newyork.cbslocal.com/2017/04/04/more-tunnels-would- 
greatly-ease-service-problems-at-penn-station-experts-say/ (accessed 20/11/2018)

CBS New York (2015) CBS2 Demanding Answers: Why Is Lincoln Tunnel Helix Construction Taking So Long? http://newyork.cbslocal.com/2015/07/14/lincolntunnel-helix-fix/ (accessed 14/07/2015)

Lehner. F (1969) Regional Organization of Transport and Urban Development. Report 1, 38th Congress of the International Union of Public Transport (UITP), London, England

Lee, Young-Jae (1998) Analysis and optimization of transit network design with integrated routing and scheduling. $\mathrm{PhD}$ dissertation, Univ. of Pennsylvania, Philadelphia

NBC New York (2017) South Tube of Lincoln Tunnel Reopens, But Hour-Long Delays Remain https://www.nbcnewyork.com/news/local/Delays-CrashInbound-South-Tube-Lincoln-Tunnel-418976494.html (accessed 20/11/2018)

New Jersey Commuter Organization (2016) It's Time for NYC to Create a Regional Transit Network That Works http://njcommuters.org/its-time-for-nyc-to-create-a-regionaltransit-network-that-works/ (accessed 23/11/2018)

New York Business Journal (2015) And the award for worst bottleneck in N.Y.C. traffic goes to... https://www.bizjournals.com/newyork/news/2015/11/23/andthe-award-for-worst-bottleneck-in-n-y-c.html (accessed 23/11/2018)

New Jersey Business Journal (2017) ReThinking the Gateway Program

http://www.njbiz.com/article/20171113/NJBIZ01/171119984/ rethinking-the-gateway-program (accessed 23/11/2018)

North New Jersey Daily News (2017) NJ Transit won't take you to Queens. But Jim Venturi will https://www.northjersey.com/story/news/columnists/christoph er-maag/2017/08/18/nj-transit-wont-take-you-queens-but-jimventuri-will/538530001/ (accessed 29/11/2018)

Rethink Studio (2017) The Regional Unified Network. Volume 1. First Step; New York, NY

Rethink Studio (2017) ReThinkNYC Regional Unified Network Overview https://vimeo.com/214381280 (accessed 10/11/2018)

The Architect Newspaper (2016) Jim Venturi and ReThinkNYC want to revolutionize how NYC handles train infrastructure https://archpaper.com/2016/05/jim-venturirethinknyc/ (accessed 22/11/2018)

Venturi Jim (2017) Simple, Big Solutions for Penn's Problems; Gotham Gazette - The Place for New York Policy and Politics. http://www.gothamgazette.com/opinion/7100-simple-bigsolutions-for-penn-s-problems (accessed 25/11/2018)

Vuchic, VR (2014) Planning, design and operation of rail transit networks; Metro Report International, pp. 48-53. London, UK.

Vuchic, VR (2005) Urban Transit: Operations, Planning, and Economics. Wiley \& Sons Publishing, Hoboken, NJ
Vuchic, VR and Musso A (1992) The Role and Organization of Transfers in Transit Networks; Proceedings of the 6th World Conference on Transport Research - WCTR, Lyon, June 1992; pp. 2177-2188

Vuchic, VR., et al. (1976) Transit operating manual, Pennsylvania Department of Transportation, Univ. of Pennsylvania, University Park, PA

Wikipedia (n.d.) Lincoln Tunnel https://en.wikipedia.org/wiki/Lincoln_Tunnel_ (accessed 25/11/2018) 